\title{
Identification of simple sequence repeat (SSR) and single nucleotide polymorphism (SNP) that are associated with the nectariless trait of Gossypium hirsutum L
}

\author{
Sang-Hyuck Park $\cdot$ Jodi A. Scheffler $\mathbb{D} \cdot$ Jeffery D. Ray $\cdot$ Brian E. Scheffler
}

Received: 29 September 2020/ Accepted: 1 March 2021/Published online: 1 April 2021

(C) This is a U.S. government work and not under copyright protection in the U.S.; foreign copyright protection may apply 2021

\begin{abstract}
Cotton (Gossypium hirsutum L.) has nectar containing modified stomates called nectaries that can be located on leaves, bracts or calyces. The nectar attracts some beneficial insects such as bees, but also predatory damaging insects such as heliothines and Lygus species. There is a naturally occurring mutation that eliminates the nectar containing nectaries and makes the cotton plants less attractive to insects. The nectariless (ne) trait is associated with a double recessive mutation of two genes $\left(n e_{1}\right.$ and $\left.n e_{2}\right)$ on homeologous chromosomes 12 and 26. Expression of the trait can be variable and is also affected by environmental conditions. This makes accurately selecting for the trait based on phenotype difficult. This study identified SSR and SNP markers that can be used by breeders for marker assisted selection (MAS) of the nectariless trait. DNA markers associated with the genes conditioning the trait and used for MAS, will
\end{abstract}

S.-H. Park · B. E. Scheffler

Genomics and Bioinformatics Research Unit, USDA-

ARS, 141 Experiment Station Road, Stoneville,

MS, USA

S.-H. Park

Institute of Cannabis Research, Colorado State University, 2200 Bonforte Blvd, Pueblo, CO, USA

J. A. Scheffler $(\bowtie) \cdot$ J. D. Ray

Crop Genetics Research Unit, USDA ARS, 141

Experimental Station Road, Stoneville,

MS, USA

e-mail: jodi.scheffler@usda.gov allow cotton cultivars to be easily developed that have decreased attractiveness to insects and reduce the need for insecticides, especially those harmful to beneficial insects such as honeybees.

Keywords Upland cotton · Gossypium hirsutum L. · Nectariless · Simple sequence repeat (SSR) $\cdot$ Single nucleotide polymorphism (SNP)

\section{Introduction}

Cotton (Gossypium spp.) is an economically important crop for fiber and seed oil production. The field crop was grown in 72 countries in 2019/2020 with a projected production of 123 million bales (US Department of Agriculture, Foreign Agricultural Service) and an estimated worth of $\$ 5.67$ billion (US Department of Agriculture, National Agriculture Statistics Service, www.nass.usda.gov). The United States is the third largest cotton producer (19.9 M bales) in the world after India (30.5 M bales) and China (27.2 M bales). The cotton crop is susceptible to numerous insect pests (Hou et al. 2013). In 2019, cotton yields were reduced by an estimated $4.47 \%$ by pest insects including fleahoppers $(0.84 \%)$, lygus $(0.83 \%)$, bollworm/budworm $(0.75 \%)$, stink bugs $(0.72 \%)$, thrips $(0.40 \%)$, spider mites $(0.28 \%)$, grasshoppers $(0.15 \%)$, aphids $(0.12 \%)$, and whiteflies $(0.07 \%)$. Total costs and losses from pest insects were estimated at $\$ 462$ 
million (Cotton insect losses 2019, entomology.msstate.edu/resources/pdf/2019/table28.pdf).

The genus Gossypium has nectar containing glands in most of its species. These nectar containing glands are called nectaries and they attract and serve as an important food source for a variety of insects. Depending on the species, nectar is produced in floral and / or extrafloral nectaries. The floral nectaries are found between the sepals and petals of the flower bud and are often absent in modern cultivated upland cotton. Extrafloral nectaries are found in the lower part of veins on the under (abaxial) side of leaves and on many modern cotton cultivars there is a nectary only on the mid-vein. Extrafloral nectaries can also be found on the calyx or below the bracts subtending the flower (Fig. 1) (Chatt et al. 2019). These nectaries are thought to be a modified form of stomata with papillae (Paiva 2017; Hu et al. 2020). The nectar is attractive not only to mutualistic symbiotic insects such as bee pollinators and protectors such as ants, but also herbivore predatory insects (Adjeimaafo and Wilson 1983). In general, nectar possessing plants have evolved strategies to both attract and repel insects, often by producing their nectar outside of the flower in extrafloral nectaries (Wackers et al. 2001; Heil 2015; Roy et al. 2017; Llandres et al.2019). Many of the insect predators of cotton are attracted to the nectar and research has demonstrated that extrafloral nectaries can enhance visitation behavior by insects (Stapel et al. 1997). When the nectaries are absent, the associated nectar is no longer produced and these "no nectary" cottons (nectariless) can be used as a biocontrol agent, by removing the nectar that attracts insect pests of cotton. The nectariless trait has been reported to confer resistance to lepidopterous species ( Lukefahr and Rhyne 1960; Holder et al. 1968), pink bollworm, Pectinophora gossypiella Saunders (Wilson and Wilson 1976; Flint et al. 1991), and tarnished plant bug, Lygus hesperus (Benedict et al. 1981).

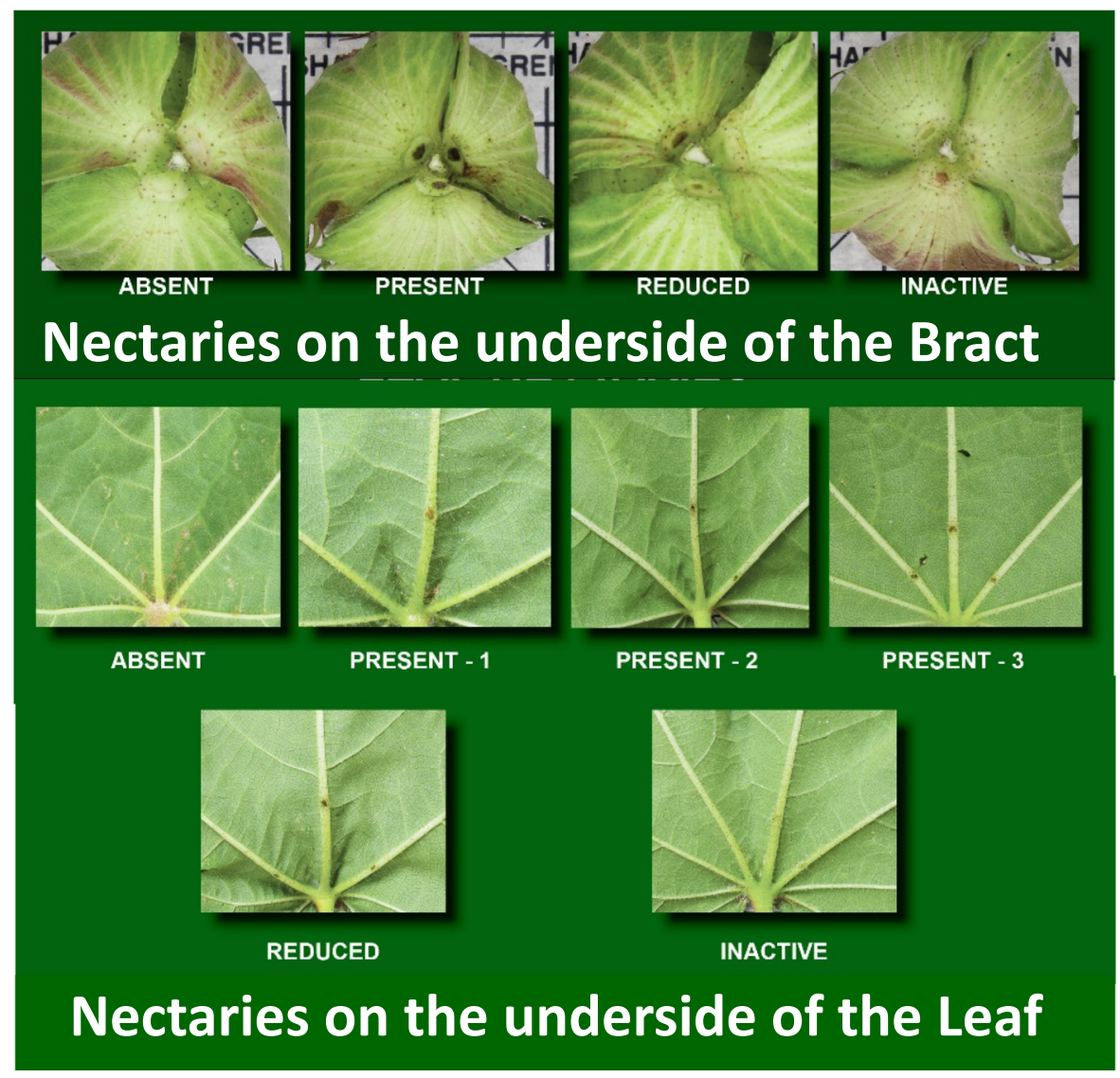

Fig. 1 Examples of bract and leaf extrafloral nectaries. Source https://www.cottongen.org/find/imagesCottonGen 
Gossypium species exist in a diploid form $(2 \mathrm{n}=2 \mathrm{X}=26)$ and a tetraploid form $(2 n=4 X=52)$. The nectariless trait has been observed in diploid forms of cotton (https://www. ars-grin.gov/), especially G. arboreum (Hu et al. 2020) which has been cultivated for over a thousand years (Du et al. 2018). However, it was almost impossible to produce viable progeny by crossing a diploid and tetraploid cotton. The nectariless trait was first observed in the tetraploid cotton Gossypium tomentosum, a wild relative of G. hirsutum. Meyer and Meyer (1961) studied the trait and attributed it to mutations in each of two genes, with the nectariless condition reflecting double-recessive mutations. They transferred the trait from $G$. tomentosum to cultivated upland cotton (G. hirsutum) by making interspecific crosses between the two species followed by backcrossing to upland cotton for four generations until nectariless lines were produced that were comparable to upland cotton. These cotton lines did not have any floral or extrafloral nectaries. Subsequent studies indicated that the nectariless trait was controlled by two genes, designated $n e_{1}$ and $n e_{2}$, located on chromosome 12 (A genome) and 26 (D genome) (Rhyne 1965; Holder et al. 1968). These two chromosomes are homeologous with approximately $40 \%$ overall physical similarities (Xu et al. 2008; Saski et al. 2017). An $n e_{2}$ physical and genetic map was constructed from an $\mathrm{F}_{2}$ population derived from the interspecific crosses between $G$. hirsutum $\times G$. tomentosum (Hou et al. 2013) and the genetic map supported previous findings that $n e_{2}$ was located on chromosome 26 (D12). A study by $\mathrm{Hu}$ et al. (2020) evaluated a diploid relative (G. arboreum) of tetraploid cotton and located an allele associated with nectaries on chromosome 12 which is analogous to the chromosome A12 of tetraploid cotton. While the location of the alleles is well documented, there remains a question as to whether the function of the two ne loci has diverged or if the genetic expression is similar. For example, is one allele more influential in the formation of leaf nectaries and the other for bract or calyx nectaries? This is the case for cotton glands, where $G l_{2}$ has a greater effect on glanding in vegetative plant parts and $G l_{3}$ has a greater influence on reproductive including seed (Lee Lee 1973; Romano and Scheffler 2008). There are also indications that epistatic effects may be in play, but most of the information to date is anecdotal.
Utilizing nectariless cotton varieties holds promise for making the crop more profitable by reducing the number of insecticide applications. An additional advantage is that it would be safer for bee populations as fewer pesticides would be applied. Since 2001, there have been commercial releases of "nectariless" cotton cultivars (Perlak et al. 2001), but because of the difficulty in selecting for the trait visually, the cultivars were a mixture of majority nectariless, but still containing a significant number of plants with leaf and / or bract nectaries. One example is MD-15 released by Meredith (2006). In the last two years, private companies have released nectariless cultivars with a low level of nectaried plants and they most likely used DNA markers to improve the efficiency of selection; however, their methods and any DNA markers are proprietary and not freely available.

Constructing $\mathrm{F}_{2}$ nectariless genetic linkage maps has been complicated due to cotton's chromosomal polyploidy with the two homeologous chromosomes being very similar and many of the same DNA markers found on both homeologs (Xu et al. 2008; Saski et al. 2017). It is also difficult to accurately score the trait phenotypically. This is because the true nectariless plants need both genes to be in the recessive form $\left(n e_{1}\right.$ and $\left.n e_{2}\right)$. Heterozygotes such as $n e_{1} n e_{1} N e_{2} n e_{2}$ or $N e_{1} n e_{1} n e_{2} n e_{2}$ can look nectariless to the naked eye especially under certain environmental conditions or developmental stage where reduced expression of the trait causes no visible nectary to be produced (Meyer and Meyer 1961). It is known that late in the growing season, leaf nectaries can be smaller or absent in some cotton varieties. There are also instances where other heterozygotes, for example $N e_{1} n e_{1} N e_{2} n e_{2}$, looks like a homozygous nectaried plant. While breeders selecting for the nectariless trait have long noted the difficulties in accurately identifying the homozygous nectariless genotypes, there are no good tools to improve their selection efficiency.

The amount of nectar in the nectary can also vary based on the time of day, environment factors such as temperature or humidity and herbivory (Wacker et al. 2001, Park et al. 2019) Unconsumed nectar can be reabsorbed with the nectar constituents recycled. In upland cotton, nectar was shown to be reabsorbed, but at a faster rate in floral nectaries than extrafloral nectaries (Cardoso-Gustavson and Davis 2015).

To facilitate nectariless trait selection, an effective selectable marker system is essential. A few attempts 
have been made to develop molecular markers, however, to date, only a couple of random amplified polymorphic DNA (RAPD) markers have been developed (Amir et al. 2002; Sajid-Ur-Rahman et al. 2008) that were generally not usable for other populations.

Molecular markers called simple sequence repeats (SSRs), also known as microsatellites, have become useful in marker-assisted selection (MAS). SSRs consist of tandem repeats of short sequences ( $2-8 \mathrm{bp})$ that are highly polymorphic, generally abundant throughout a genome, and co-dominant (Joobeur et al. 2000; Palombi and Damiano 2002). SSR-derived genotypic polymorphism can be detected using PCR-based systems and the SSR analysis can be automated using DNA sequencers, thereby enabling simultaneous processing of multiple markers at different loci. This high-throughput analysis enables SSR marker use for genetic map construction (Liu et al. 2000). In addition, SSRs serve to fill the gap between genome sequence and genetic mapping (Schuler 1998). SSRs can also provide a framework for highresolution marker-based map construction utilizing single nucleotide polymorphisms (SNPs). To date, a total of 78,340 SSR markers are publicly available in the CottonGen database (Yu et al. 2014) and a number of these can be localized to the cotton chromosomes (Saski et al. 2017).

Unlike SSR markers, a SNP is a genetic polymorphism caused by single nucleotide change. SNPs are the most abundant DNA markers available in Gossypium spp. where genetic diversity is limited (Kottapalli et al. 2016). With the development of next generation sequencing (NGS) technology, the number of identified SNP collections has increased and high-throughput data analysis has become easier. A CottonSNP63K array (SNP Chip) was developed for SNP marker development. The array contains 45,104 putative intra-specific SNPs and 17,954 putative inter-specific SNPs, enabling analysis of a mapping population derived not only from a cross within G. hirsutum L. but also crosses with other cotton species (Hulse-Kemp et al. 2015).

Here we report the development of a genetic map using representative sets of SSR and SNP markers to genotype $256 \mathrm{~F}_{2}$ lines derived from crosses between nectaried and nectariless cotton lines. In this study, a total of 20 polymorphic SSR markers, selected based on their location on Chromosome 12 or 26 , along with $63 \mathrm{~K} \mathrm{SNPs}$ were used to construct a nectariless linkage map to identify molecular genetic markers that can be used to improve the selection efficiency for the nectariless trait, often referred to as marker assisted selection (MAS).

\section{Materials and methods}

Cotton plants used and genomic DNA preparation

The cotton lines used were obtained from the USDA ARS Stoneville, Mississippi cotton collection and grown at Stoneville. MD26ne was released as a cultivar (Meredith 2013). The pedigrees of the other lines are described in Romano and Scheffler (2008). Because of the difficulty in accurately phenotyping the nectariless trait, the nectariless parents used to create the $F_{2}$ progeny were tested before using. Twenty plants each of MD26ne, A1006ne and FM832ne were grown and scored for extrafloral nectaries associated with the leaves, bracts and calyces. None of the parental lines had floral nectaries. From each cotton line, five individual plants with the nectariless phenotype were self pollinated. Seed from these plants were grown out the following field season in a progeny row and scored again for the nectariless phenotype. Individual plants from progeny rows where all the plants scored as nectariless were used as the parents in crosses to develop the $F_{2}$ populations. Population size was determined by how many $F_{2}$ seed were produced from the $F_{1}$ plant.

For SSR analysis, a total of $175 \mathrm{~F}_{2}$ individuals were used for nectariless genotyping as well as 17 parents used as controls and for validation. To be able to detect variation within the parental types not due to the nectariless trait, two plants each of MD26ne, A1006ne, JACOgl, STVgl and FM832ne were used along with four plants of Mac7_0238 and three plants of Mac7_1238. The $F_{2}$ populations were derived from crosses between MD26ne $\left(n e_{1} n e_{2}\right)$ and Mac7_1238 $\left(N e_{1} N e_{2}\right)$, yielding $100 \mathrm{~F}_{2}$ progeny and MD26ne $\left(n e_{1} n e_{2}\right) \times$ Mac7_0238 $\left(N_{1} N e_{2}\right)$, yielding $75 \quad \mathrm{~F}_{2}$ progeny. Later when the $63 \mathrm{~K} \mathrm{SNP} \mathrm{Chip} \mathrm{array} \mathrm{became}$ available, additional $F_{2}$ populations were developed and analyzed. A total of $259 \mathrm{~F}_{2}$ individuals and 25 parental types were used and analyzed on a 288 SNP Chip array. To be able to detect variation within the parental types not due to the nectariless trait, three plants of MD26ne, A1006ne, JACOgl, STVgl and 
Table 1 SSR markers used for nectariless linkage map construction

\begin{tabular}{|c|c|c|c|}
\hline & SSR markers & Chromosome & Primer sequence $\left(5^{\prime}-3^{\prime}\right)$ \\
\hline 1 & BNL3482 & AD_CH20, 26 & $\begin{array}{l}\text { BNL3482_F: ATTTGCCCCAGGTTTTTTTT } \\
\text { BNL3482_R: GCAACACCTTTTCCTCCCTA }\end{array}$ \\
\hline 2 & DPL0380 & AD_CH12, 26 & $\begin{array}{l}\text { DPL0380_F: GCTAATTGCTCTCTAGGCAAAGAC } \\
\text { DPL0380_R: CAACTGCTTCCACCTAGGATAAGT }\end{array}$ \\
\hline 3 & CGR5793 & AD_CH26 & $\begin{array}{l}\text { CGR5793_F: CACCAAGCACTCTAGAAACTGAAA } \\
\text { CGR5793_R: TATGCTTCTTGCACGCAGTT }\end{array}$ \\
\hline 4 & CGR6149 & AD_CH26 & $\begin{array}{l}\text { CGR6149_F: CACCATACCGAGCTACTCCAG } \\
\text { CGR6149_R: ATCGTTCCAAGCAAACCAAC }\end{array}$ \\
\hline 5 & CGR6471 & AD_CH26 & $\begin{array}{l}\text { CGR6471_F: AATGGCAATCCCAGCACTAC } \\
\text { CGR6471_R: TCTGCTTGCTCTGTTCCTCA }\end{array}$ \\
\hline 6 & CGR6651 & AD_CH26 & $\begin{array}{l}\text { CGR6651_F: CCAAACCCACAATTTCTGCT } \\
\text { CGR6651_R: GGGACTCTCTTAGGGCCAGT }\end{array}$ \\
\hline 7 & CGR6759 & AD_CH26 & $\begin{array}{l}\text { CGR6759_F: CGACCCATCCGATAGCAATA } \\
\text { CGR6759_R: AAACAGAGAGGTGTCGACGG }\end{array}$ \\
\hline 8 & DC30183c & AD_CH26 & $\begin{array}{l}\text { DC30183_F: CTTTGGCGATCATTTCAG } \\
\text { DC30183_R: CATGGCGAGTTTTATCCA }\end{array}$ \\
\hline 9 & DPL0250 & AD_CH26 & $\begin{array}{l}\text { DPL0250_F: CATAGGCATCTGAAAGTGAATGG } \\
\text { DPL0250_R: GGCTTAAACAAGTAAGCAATCACC }\end{array}$ \\
\hline 10 & DPL0404b & AD_CH26 & $\begin{array}{l}\text { DPL0404_F: TCATCTACCATAGCCCTTGAAGTT } \\
\text { DPL0404_R: GAAGAACCCTTCCATCAAGAATGT }\end{array}$ \\
\hline 11 & DPL0208a & AD_CH26 & $\begin{array}{l}\text { DPL0208_F: CTTATTGGGTTCTGCTAAGGTTGA } \\
\text { DPL0208_R: GGATTCTTACCTCAACATGGATTC }\end{array}$ \\
\hline 12 & CIR0167 & AD_CH26 & $\begin{array}{l}\text { CIR167_F: CGCTCGGTTATTTAGTTT } \\
\text { CIR167_R: AAATTCCAGCTCATGGT }\end{array}$ \\
\hline 13 & CIR0293 & AD_CH12 & $\begin{array}{l}\text { CIR293_F: CCGCTTTATCACATCTCT } \\
\text { CIR293_R: GGTTGTCTTTCAGTTTGG }\end{array}$ \\
\hline 14 & DPL0204 & AD_CH12 & $\begin{array}{l}\text { DPL0204_F: AGTTGAGGCAGTGGTGTACAGTTA } \\
\text { DPL0204_R: TTGGAGAGGGAGAGAGACTATGAC }\end{array}$ \\
\hline 15 & BNL2495 & AD_CH26 & $\begin{array}{l}\text { BNL2495_F: ACCGCCATTACTGGACAAAG } \\
\text { BNL2495_R: AATGGAATTTGAACCCATGC }\end{array}$ \\
\hline 16 & DPL0379 & AD_CH12, 26 & $\begin{array}{l}\text { DPL0379_F: CACCAGATGGAAGGGAAGATATAA } \\
\text { DPL0379_R: GTTCTCCTGAGATTGTAAGTCATGC }\end{array}$ \\
\hline 17 & DPL0565 & AD_CH12, 26 & $\begin{array}{l}\text { DPL0565_F: CGACCATCATAATGAAAGAGAAGG } \\
\text { DPL0565_R: GCAAGCCAAAGTATCTTGTCACAT }\end{array}$ \\
\hline 18 & CGR6012 & AD_CH12 & $\begin{array}{l}\text { CGR6012_F: ATGTGCCTTGTCCTCTTCCA } \\
\text { CGR6012_R: GGGATGTGAGGGCATCATAG }\end{array}$ \\
\hline 19 & CGR6880 & AD_CH26 & $\begin{array}{l}\text { CGR6880_F: CGGCTGTATTTGTTTGGTGC } \\
\text { CGR6880_R: GGGATGTGAGGGCATCATAG }\end{array}$ \\
\hline 20 & CER0144 & AD_CH12 & $\begin{array}{l}\text { CER0144_F: TACGCCGGGTTACTTTTGAG } \\
\text { CER0144_R: ATCGGCAACAATGGTGTTTT }\end{array}$ \\
\hline
\end{tabular}

\section{Markers DPL0379 and}

DPL0565 were identified as linked to the nectariless trait in this study progeny, POP2), A1006ne $\left(n e_{1} n e_{2}\right) \times \mathrm{JACOgl}\left(\mathrm{Ne}_{1-}\right.$ $\mathrm{Ne}_{2}$ ) (69 $\mathrm{F}_{2}$ progeny, POP3) and STVgl $\left(\mathrm{Ne}_{1} \mathrm{Ne}_{2}\right)$ $\times$ FM832ne $\left(n e_{1} n e_{2}\right)\left(50 \mathrm{~F}_{2}\right.$ progeny, POP4). Leaf
FM832ne were used and five plants each of Mac7_0238 and Mac7_1238. The $F_{2}$ individuals were from crosses between MD26ne $\times$ Mac7_1238 $\left(69 \mathrm{~F}_{2}\right.$ progeny, POP1), MD26ne $\times$ Mac7_0238 (71 $F_{2}$ 
tissue was collected from each plant for DNA extraction.

Genomic DNA extraction was conducted using a NucleoSpin Plant II kit (MN Inc., Bethlehem, PA). Briefly a young leaf, $2 \mathrm{~cm}$ in diameter, was ground using a FastPrep 24 homogenizer (MP Biomedical, Santa Ana, CA) for $1 \mathrm{~min}$. Homogenized leaf samples were mixed with $600 \mu \mathrm{l}$ Buffer PL2 and vortexed for at least $10 \mathrm{~s}$. Then $20 \mu \mathrm{l}$ RNase A was added and incubated at $65{ }^{\circ} \mathrm{C}$ for $30 \mathrm{~min}$ after gentle mixing. Afterwards $150 \mu$ Buffer PL3 was added and mixed and incubated on ice for $5 \mathrm{~min}$ then centrifuged for $5 \mathrm{~min}$ at $11,000 \times \mathrm{g}$. The supernatant was transferred to a NucleoSpin Filter (purple) in a collection tube and centrifuged for $2 \mathrm{~min}$ at $11,000 \times \mathrm{g}$. Then $900 \mu \mathrm{l}$ Buffer PC was added to the flow through after mixing thoroughly, then $700 \mu$ was transferred to the NucleoSpin Plant II Column (green). The column was centrifuged for $1 \mathrm{~min}$ at $11,000 \times \mathrm{g}$ and the flow through was discarded. The column was washed with $400 \mu \mathrm{l}$ of PW1 and rinsed with PW2 buffer with $700 \mu \mathrm{l}$ and $200 \mu \mathrm{l}$ for $1 \mathrm{~min}$ and 2 min respectively. The DNA pellets were eluted with $50 \mu$ l of prewarmed PE buffer. The DNA was quantified by a NanoDrop micro-spectrophotometer (Thermo Scientific, Wilmington, DE).
Fig. 2 Linkage analyses of SNPs that were found to be associated with the nectariless trait by Single Marker Analysis (SMA). The analyses included marker trait association (MTA) analysis, and interval mapping (IM). The graphs represent SNPs distributions on the chromosomes and location of the nectariless co-located SSR QTL on Chr. 26

Nectary/nectariless phenotypic scoring

All the nectaried parents had bract nectaries and leaf nectaries, but no floral or calyx nectaries (Fig. 1). This is common among modern cotton lines (Llandres et al. 2019). While the association of extrafloral nectaries with the $\mathrm{Ne}_{1}$ and $\mathrm{Ne}_{2}$ is well documented, floral nectary genetics is not as clear and may require additional alleles to express nectaries in the flowers (Chatt et al. 2019). While tetraploid cotton plants with the confirmed $n e_{1} n e_{1} n e_{2} n e_{2}$ genotype have no floral or extrafloral nectaries, expression of bract nectaries in heterozygous plants may vary with the cotton variety, age of the plant or time of the season. Scoring leaves for nectaries at mid flower is considered the most reliable method to determine phenotype. However, because of the difficulty of seeing the nectaries with the naked eye, leaves were collected from the field and

Table 2 Descriptive statistics for $\mathrm{F}_{2}$ phenotypic scores resulting from the cross between a nectariless parent and a nectaried parent

\begin{tabular}{|c|c|c|c|c|c|c|c|c|}
\hline \multirow[t]{2}{*}{ Population } & \multirow[t]{2}{*}{$\mathrm{N}^{\mathrm{a}}$} & \multicolumn{3}{|c|}{ Genotypes } & \multicolumn{4}{|c|}{ With Yates correction } \\
\hline & & $\begin{array}{l}\text { Nectary } \\
(\mathrm{Ne})\end{array}$ & $\begin{array}{l}\text { Hetero- } \\
\text { zygous } \\
(\text { Nene })\end{array}$ & $\begin{array}{l}\text { Nectari- } \\
\text { less } \\
(n e)\end{array}$ & $\begin{array}{l}\text { Chi-square } \\
p \text { value } \\
1: 1\end{array}$ & $\begin{array}{l}\text { Chi-square } \\
p \text { value } \\
11: 5\end{array}$ & $\begin{array}{l}\text { Chi-square } p \\
\text { value } \\
9: 7\end{array}$ & $\begin{array}{l}\text { Chi-square } \\
p \text { value } \\
15: 1\end{array}$ \\
\hline F2-POP1 & 69 & 13 & 23 & 33 & 0.81 & 0.01 & 0.57 & 0.00 \\
\hline $\begin{array}{l}\text { MD26ne } \mathrm{e}^{\mathrm{b}} \times \mathrm{Mac} 7 \\
1238 \mathrm{Ne}^{\mathrm{c}}\end{array}$ & & 36 & & & & & & \\
\hline F2-POP2 & 71 & 40 & 10 & 21 & 0.00 & 0.86 & 0.02 & 0.00 \\
\hline $\begin{array}{l}\text { MD26ne } \mathrm{e}^{\mathrm{b}} \times \mathrm{Mac} 7 \\
0238 \mathrm{Ne}^{\mathrm{c}}\end{array}$ & & 50 & & & & & & \\
\hline F2-POP3 & 69 & 16 & 23 & 30 & 0.34 & 0.04 & 0.94 & 0.00 \\
\hline A1006ne $e^{b} \times J_{A C O g I N e}{ }^{c}$ & & 39 & & & & & & \\
\hline $\mathrm{STVglNe}^{\mathrm{c}} \times \mathrm{FM} 832 \mathrm{ne}^{\mathrm{b}}$ & 50 & 36 & 12 & 2 & 0.00 & 0.00 & 0.00 & 0.72 \\
\hline F2-POP4 & & 48 & & & & & & \\
\hline
\end{tabular}

${ }^{a}$ Number of individual plants

${ }^{\mathrm{b}}$ ne, Nectariless (no nectaries)

${ }^{\mathrm{c}} \mathrm{Ne}$, Cotton with leaf nectary

${ }^{\mathrm{d}}$ Yates continuity correction for small population size 
MD26ne x Mac7 1238 Chr. 12

MD26ne x Mac7 1238 Chr. 26
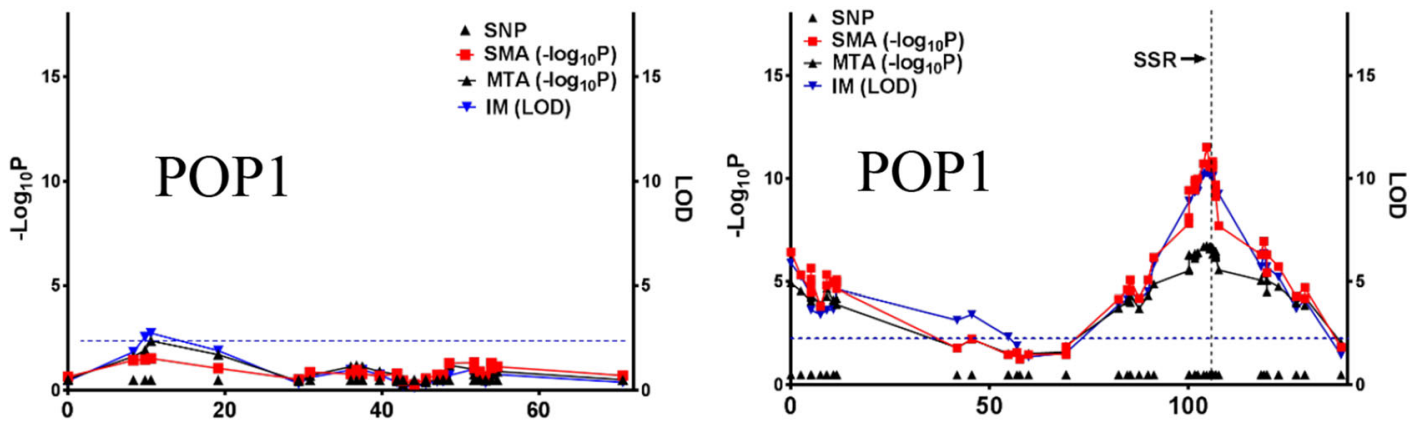

MD26ne x Mac7 0238 Chr. 12

MD26ne x Mac7 0238 Chr. 26
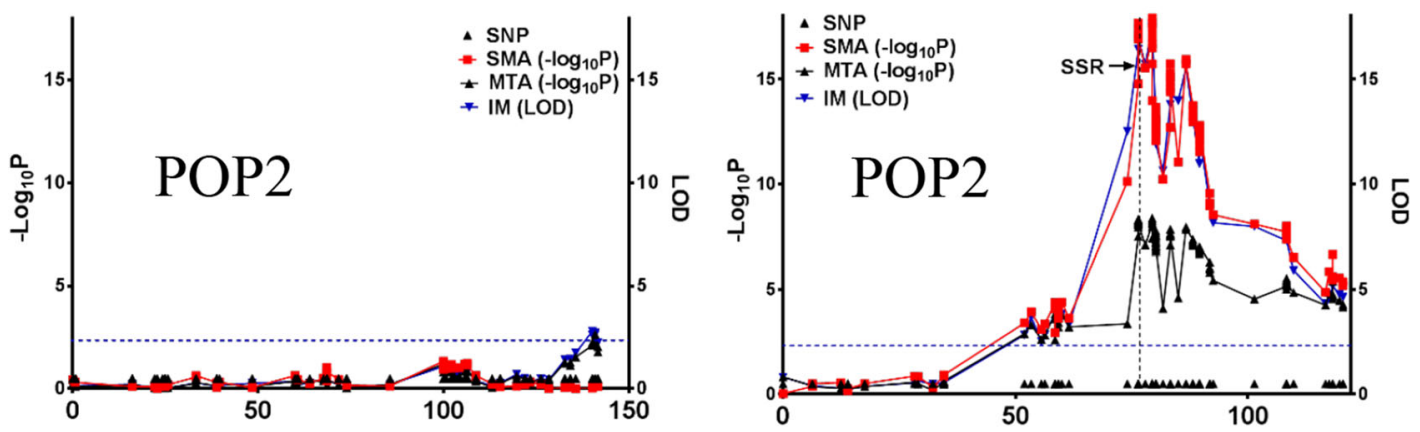

A1006ne x JACOgl Chr. 12

A1006ne x JACOgl Chr. 26
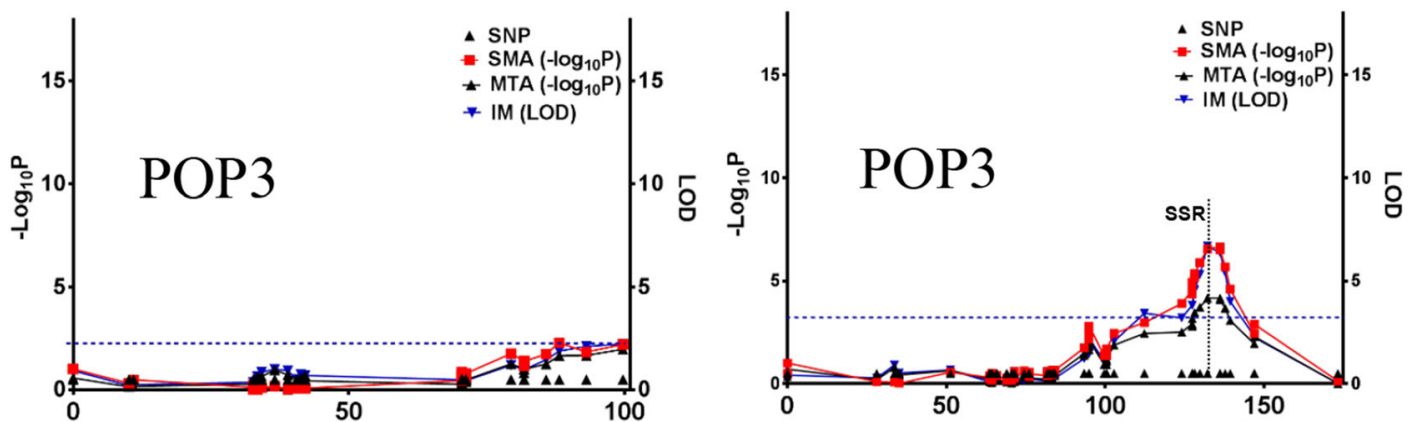

STVgl x FM832ne Chr. 12

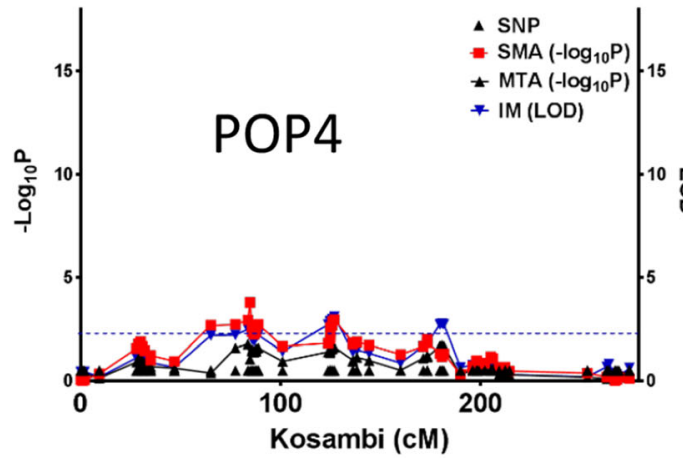

STVgl x FM832ne Chr. 26

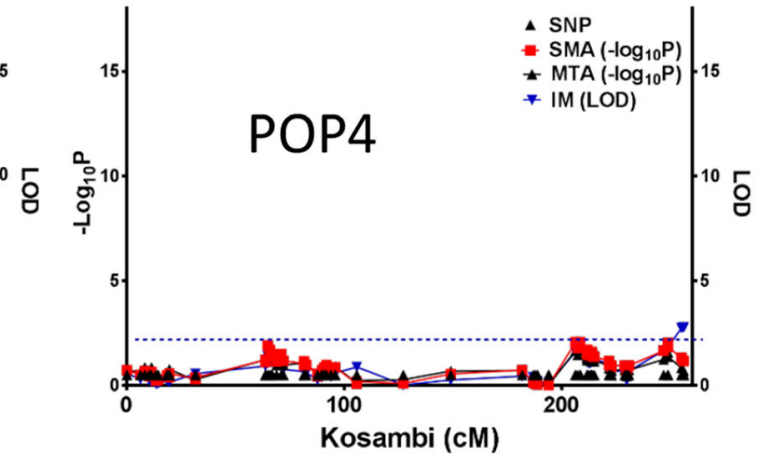




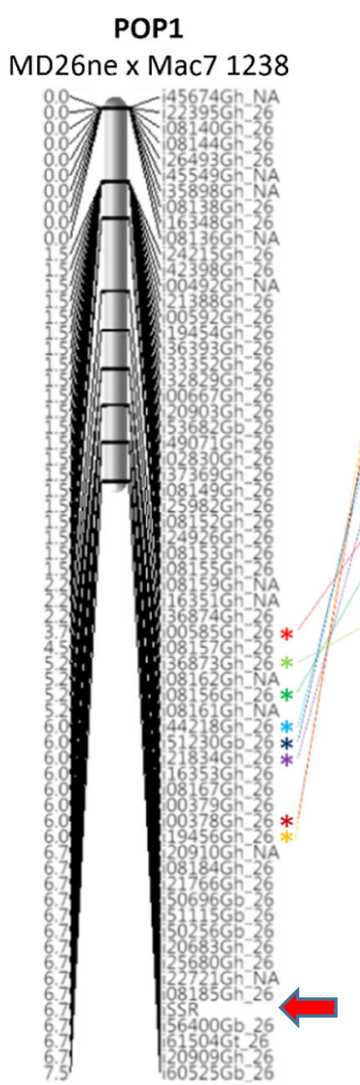

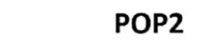

MD26ne x Mac7 0238
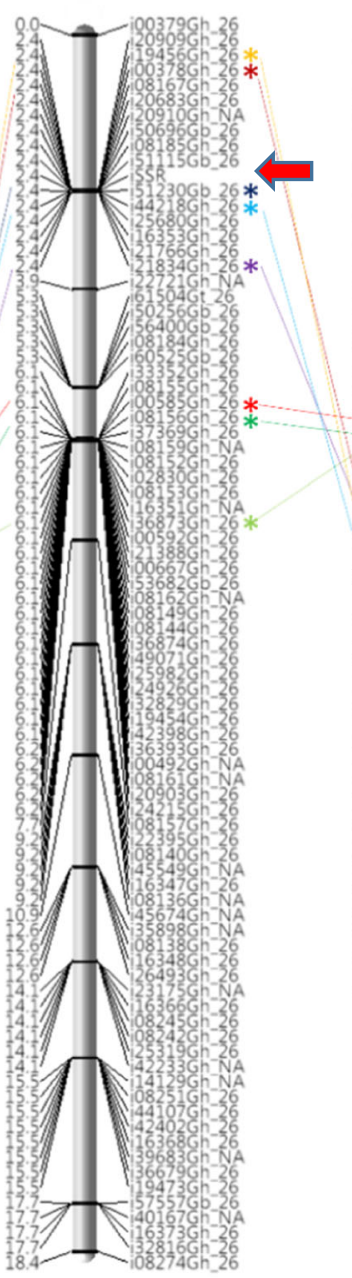

SSRs DPL0379 and DPL0565 were co-located and indicated by the red arrows.
Consensus Linkage Map

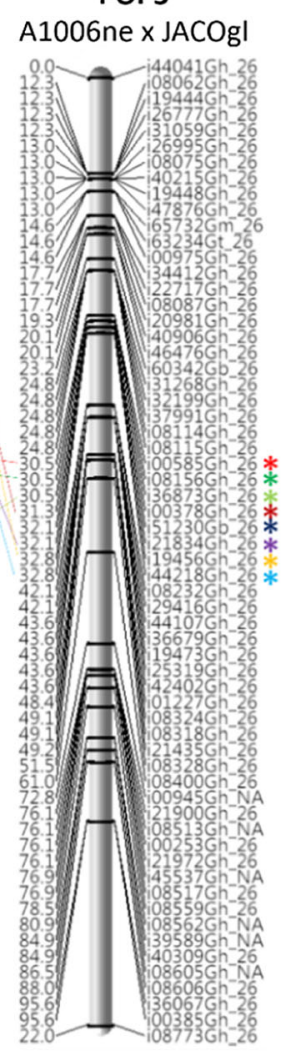

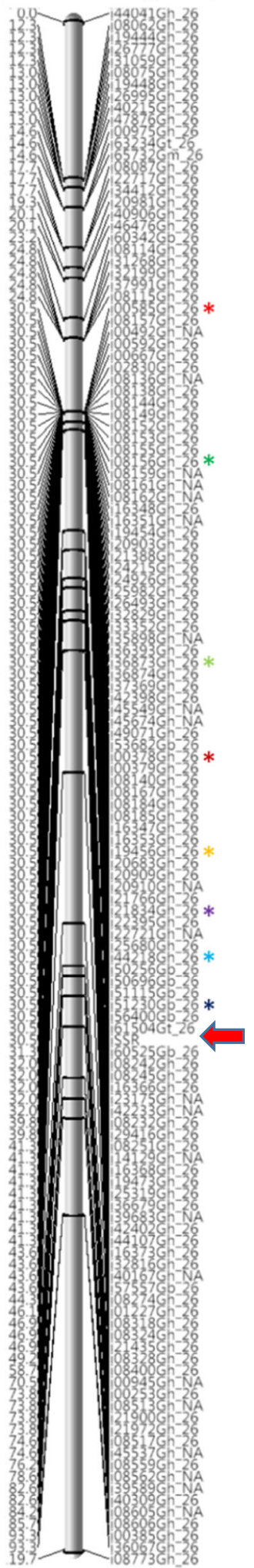


4 Fig. 3 Nectariless QTL linkage map on Chr. 26. The asterisk indicates SNPs that are shown consistently throughout POP1-3 and the colored line indicates SNP location. The consensus linkage group is the integrated map of POP1-3. Linkage calculations and integration of maps were calculated using JMP Genomics 8.0 (SAS Institute, Cary NC)

scored in the lab using a Keyence Digital Microscope (Keyence Corp., Itasca, IL) at $10 \times$ magnification. The leaves were collected in early July when the plants were at mid flower and expression of nectaries was at its peak. Leaves measured 5 to $7 \mathrm{~cm}$ across the leaf blade and were collected from a floral branch near the top of the plant. Phenotypic scoring for nectaries was done by viewing the lower mid-vein located on the abaxial side of leaf. Two leaves were scored from each plant. The leaves were first scored using a standardized system as follows; 0- no nectaries, 1- starting to bump out from vein, 2- a ridge along two sides and sunken pad with no nectar, 3- more defined oval ridge and sunken pad with nectar, 4- well defined oval ridge with a wide open shape and sunken pad with nectar. For the final scoring used for mapping, scores 1-3 were considered some combination of $\mathrm{Ne}$ and ne and therefore heterozygous.

That resulted in three classes: homozygous nectaried $\left(\mathrm{Ne}_{1} \mathrm{Ne}_{1} \mathrm{Ne}_{2} \mathrm{Ne} 2\right)$; heterozygous $\left(\mathrm{Ne}_{1} \mathrm{Ne}_{1} n e_{2} \mathrm{ne}_{2}\right.$ or $n e_{1} n e_{1} \mathrm{Ne}_{2} \mathrm{Ne} e_{2}$ etc.); and homozygous nectariless $\left(n e_{1} n e_{1} n e_{2} n e_{2}\right)$. Nectaries on bracts subtending the flower buds were also scored and compared to the leaf scores, but were not considered reliable enough to use for mapping. The leaves scored as nectariless also scored as nectariless for bract nectaries.

\section{Genotyping with SSR and SNP markers}

A total of 20 polymorphic SSR primers, preselected for their location on chromosome 12 or 26, were tested to determine if they were linked to the nectariless trait. The SSR primer sequences used in this study were obtained from the CottonGen (http://www.cottongen. org/) database and primer details are described in Table 1. For genotyping, extracted total genomic DNA was standardized to $10 \mathrm{ng} / \mathrm{ul}$ and PCR analysis conducted using a Multiplex PCR Kit (QIAGEN, Valencia, CA). Prior to DNA fragment analysis, the PCR products were mixed with formamide and size standard labeled with ROX reference dye (Life
Technologies, Grand Island, NY) using a robotic liquid handling system (Hamilton Robotics, Reno, NV). The mixed samples were then injected into an ABI 3730XL analyzer (Life Technologies, Grand Island, NY) and the genotypes were analyzed by GeneMapper5 (Life Technologies, Grand Island, NY).

For the SNP assay, an Illumina BeadArray ${ }^{\mathrm{TM}}$ chip with $63 \mathrm{~K} \mathrm{SNPs}$ was used to explore which SNPs were associated with the nectariless trait (Hulse-Kemp et al. 2015). The dsDNA was quantified using a Quant-iT ${ }^{\mathrm{TM}}$ PicoGreen ${ }^{\circledR}$ dsDNA Assay Kit (Thermo Scientific, Wilmington, DE). The SNP chip analyses were conducted by GeneSeek (Neogen Genomics, Lincoln, NE) or Texas A\&M (College Station, TX). Quality filtering of SNP markers was performed by removing SNPs with (i) greater than $10 \%$ missing by locus (ii) allele frequency less than $1 \%$ and (iii) excess heterozygosity (a Hardy-Weinberg equilibrium p-value less than 0.0001). After filtering, approximately 8,000 SNPs remained for analysis.

Linkage analysis and genetic map construction

A series of linkage analyses including QTL single marker analysis (SMA), marker trait analysis (MTA), interval mapping (IM), and genetic map construction were performed using JMP Genomics 8.0 (SAS Institute, Cary NC). Recombination values were converted to genetic distances (cM) using the Kosambi mapping function. QTL SMA was performed to examine the regression of SNP markers and trait values. The regression is represented as the $-\log _{10}$ (probability) which is $-\log _{10}(0.01)=2.0$ and used as a threshold of significance. Interval mapping was conducted to find putative QTLs on any genomic location flanked by two markers. IM uses the conditional probabilities of a QTL given two observed markers in the regression model to distinguish the genetic effects of a QTL from the genetic effect due to linkage (SAS Institute). The genetic map was evaluated every $2.0 \mathrm{cM}$ to identify putative QTL using EM Algorithm (SAS Institute 2015a, b). A threshold LOD ( $\log$ of odd) value of $3.5(\mathrm{P}<0.05)$ was used to declare presence of QTL. The nectariless QTL was considered at the position with the maximum LOD score on the linkage group. To confirm the putative QTL locus on Chromosome 26, MTA analysis was conducted on ordinal trait values. The significance of putative association is reported as the $-\log _{10}(\mathrm{P})$ and a 
conservative $-\log _{10} 2.0$ level was used as a threshold of significance. A linkage map for each population and its consensus linkage map were constructed using JMP Genomics 8.0 on SNPs identified using 4 mapping populations (POP1-4). The SNPs showing significant trait associations were positioned on Chr. 26 and each linkage was then merged to generate a consensus linkage map.

\section{Results}

\section{Phenotypic evaluation of the $F_{2}$ generation}

We used a total of 4 mapping populations (POP1-4) for nectariless linkage map construction and evaluated a total of $259 \mathrm{~F}_{2}$ plants (Table 2). The leaf phenotype of each $\mathrm{F}_{2}$ plant was scored as homozygous with nectaries, heterozygous with small or vestigial nectaries or homozygous nectariless (no nectaries). The observed scores are presented in Table 2. Previous studies have reported that the nectariless trait is controlled by two recessive alleles $\left(n e_{1}\right.$ and $n e_{2}$ ). While it is confirmed that a plant with the $n e_{1} n e_{1} n e_{2-}$ $n e_{2}$ genotype is nectariless, there are indications that epistasis may influence expression of the trait which makes phenotypic scoring more complicated. For example, if the trait only requires one of the genes to be dominant $\left(\mathrm{Ne}_{1}\right.$ or $\left.\mathrm{Ne}_{2}\right)$, the expected phenotypic segregation ratio would be 15:1. Having more nectariless phenotypes than expected has been frequently observed by the authors and others in their breeding programs. This could be because heterozygotes such as $\mathrm{Ne}_{(1}$ or $2_{2}$ nenene are phenotypically nectariless. Further complicating the scoring is the belief that environmental conditions can also affect the expression of the trait and the resulting phenotypic score. While the exact allele is not clear, all the populations exhibited some type of digenic epistasis based on Chisquare analysis.

\section{SSR marker validation}

A total of 20 polymorphic SSR primer pairs (Table 1) previously assigned to Chr. 12 and / or Chr. 26. were used to analyze $175 \mathrm{~F}_{2}$ plants from a cross between MD26ne x Mac7 1238Ne (POP1) or MD26ne x Mac7 $0238 \mathrm{Ne}$ (POP2). Seventeen parental lines were also used for validation and controls in the nectariless QTL search. The 38 amplicons which were amplified by the set of SSR primers were analyzed by GeneMapper. Only two polymorphic SSR markers, DPL0379 and DPL0565 were associated with the leaf nectariless trait. The two SSRs showed an identical genotypic segregation pattern in $\mathrm{F}_{2}$ plants. The trait association was validated through QTL SMA, MTA, interval mapping (IM) and in the integration with SNP markers. A series of QTL linkage analyses indicated that the two SSR markers were co-located in the nectariless QTL region residing on Chr. 26 for three of the mapping populations (POP1-3) (Fig. 2, 3).

\section{SNP data processing}

Because of the high degree of sequence similarity between Chr. 12 and Chr. 26 (Saski et al. 2017) and the fact that an SSR marker often amplifies fragments on both chromosomes, analysis can be difficult. The other challenge is the low number of polymorphic SSR markers available. When the CottonSNP63K array became available, we were able to partially overcome these challenges and the 63,058 SNPs were used to analyze DNA samples from a total of $259 \mathrm{~F} 2$ progeny plants from 4 mapping populations (POP1-4). There were also 25 parental lines included as controls on the SNP arrays. Prior to the linkage analyses, noninformative SNPs were removed based on following criteria; 1) missing data was more than $10 \%$, 2) parental genotypes were either identical or had missing data, 3) F2 offspring were monomorphic. For the SNP quality processing, SNPs known to be located on Chr. 12 and 26 as well as SNPs with unknown locations were included. The final number of SNPs after data processing is listed on Table 3.

\section{QTL linkage analyses on Chr. 12 and 26}

The association of each SNP marker with the nectariless trait was examined by a QTL single marker analyses (SMA). The SMA uses a regression model to assess marker-trait associations at individual marker locus and calculate the probability of QTL evidence for each marker. All SNPs that passed quality controls (Table 3) were used in the SMA (over 3,000 each for POP1, POP2, and POP4 and over 1700 for POP3). Results identified 72 and 138 SNPs from POP1, 122 and 137 SNPs from POP2, 74 and 68 SNPs from POP3, and 180 and 165 SNPs from POP4 that were 


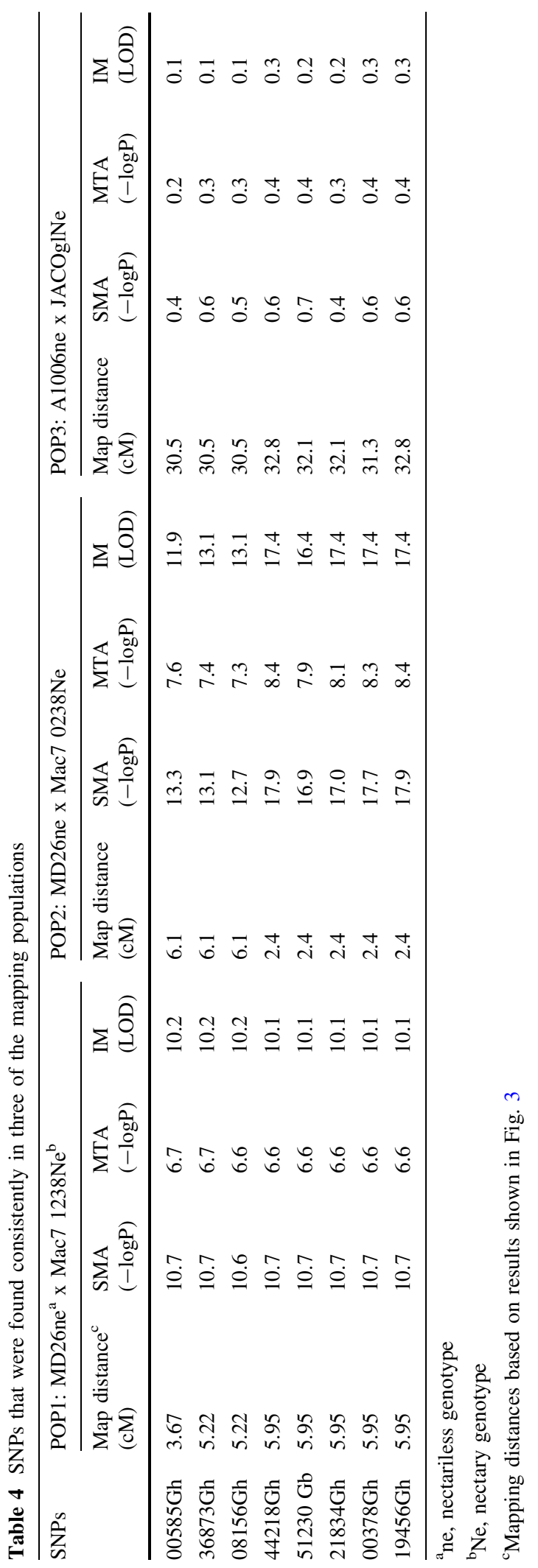


Table 5 SNP and SSR markers linked to the nectariless trait in POP1 and POP2. Highlighted markers are the most significantly associated with the nectariless trait. SNP designations ending with "NA" were previously unassigned to a specific chromosome

\begin{tabular}{|c|c|c|c|c|c|c|c|c|c|c|}
\hline & \multicolumn{5}{|c|}{ POP1: MD26ne x Mac7 1238Ne } & \multicolumn{5}{|c|}{ POP2: MD26ne x Mac7 0238Ne } \\
\hline & SNPs & $\begin{array}{l}\text { Kosambi } \\
\text { (cM) }\end{array}$ & $\begin{array}{l}\text { SMA } \\
(-\log \mathrm{P})\end{array}$ & $\begin{array}{l}\text { MTA } \\
(-\log \mathrm{P})\end{array}$ & $\begin{array}{l}\text { IM } \\
\text { (LOD) }\end{array}$ & SNPs & $\begin{array}{l}\text { Kosambi } \\
\text { (cM) }\end{array}$ & $\begin{array}{l}\text { SMA } \\
(-\log \mathrm{P})\end{array}$ & $\begin{array}{l}\text { MTA } \\
(-\log \mathrm{P})\end{array}$ & $\begin{array}{l}\text { IM } \\
\text { (LOD) }\end{array}$ \\
\hline 1 & 08157Gh_26 & 4.5 & 11.5 & 6.8 & 10.3 & 08184Gh_26 & 5.3 & 17.7 & 8.3 & 16.9 \\
\hline 2 & 00379Gh_26 & 6.0 & 10.8 & 6.3 & 10.1 & 25680Gh_26 & 2.4 & 17.7 & 8.3 & 16.4 \\
\hline 3 & 08162Gh_NA & 5.2 & 10.7 & 6.7 & 10.2 & 20910Gh_NA & 2.4 & 17.4 & 8.2 & 17.4 \\
\hline 4 & 08161Gh_NA & 5.2 & 10.7 & 6.7 & 10.2 & $50256 \mathrm{~Gb} \_26$ & 5.3 & 17.4 & 8.2 & 16.9 \\
\hline 5 & 08167Gh_26 & 6.0 & 10.7 & 6.6 & 10.1 & 56400Gb_26 & 5.3 & 17.4 & 8.2 & 16.9 \\
\hline 6 & 16353Gh_26 & 6.0 & 10.5 & 6.6 & 10.1 & 16353Gh_26 & 2.4 & 17.2 & 8.1 & 16.4 \\
\hline 7 & 08159Gh_NA & 2.2 & 10.0 & 6.4 & 9.4 & 50696Gb_26 & 2.4 & 17.2 & 8.1 & 16.4 \\
\hline 8 & 16351Gh_NA & 2.2 & 10.0 & 6.4 & 9.4 & 51115Gb_26 & 2.4 & 17.2 & 8.1 & 16.4 \\
\hline 9 & 36874Gh_26 & 2.2 & 10.0 & 6.4 & 9.4 & SSR & 2.4 & 17.1 & 8.3 & 16.4 \\
\hline 10 & 24215Gh_26 & 1.5 & 9.9 & 6.3 & 9.3 & 61504Gt_26 & 5.3 & 17.0 & 8.1 & 16.9 \\
\hline 11 & 42398Gh_26 & 1.5 & 9.9 & 6.3 & 9.3 & 21766Gh_26 & 2.4 & 16.9 & 8.2 & 16.4 \\
\hline 12 & 00492Gh_NA & 1.5 & 9.9 & 6.3 & 9.3 & 08185Gh_26 & 2.4 & 16.7 & 8.1 & 17.4 \\
\hline 13 & 21388Gh_26 & 1.5 & 9.9 & 6.3 & 9.3 & 20683Gh_26 & 2.4 & 16.5 & 8.1 & 17.4 \\
\hline 14 & 00592Gh_26 & 1.5 & 9.9 & 6.3 & 9.3 & 08136Gh_NA & 9.2 & 15.9 & 7.9 & 15.5 \\
\hline 15 & 19454Gh_26 & 1.5 & 9.9 & 6.3 & 9.3 & 26493Gh_26 & 12.6 & 15.7 & 7.8 & 13.8 \\
\hline 16 & 36393Gh_26 & 1.5 & 9.9 & 6.3 & 9.3 & 16348Gh_26 & 12.6 & 15.7 & 7.8 & 15.5 \\
\hline 17 & 33352Gh_26 & 1.5 & 9.9 & 6.3 & 9.3 & 08167Gh_26 & 2.4 & 15.7 & 8.0 & 17.4 \\
\hline 18 & 32829Gh_26 & 1.5 & 9.9 & 6.3 & 9.3 & 22721Gh_NA & 3.9 & 15.5 & 7.1 & 15.7 \\
\hline 19 & 00667Gh_26 & 1.5 & 9.9 & 6.3 & 9.3 & 08138Gh_26 & 12.6 & 15.1 & 7.5 & 13.8 \\
\hline 20 & 53682Gb_26 & 1.5 & 9.9 & 6.3 & 9.3 & 35898Gh_NA & 12.6 & 14.9 & 7.6 & 14.3 \\
\hline 21 & 49071Gh_26 & 1.5 & 9.9 & 6.3 & 9.3 & 20909Gh_26 & 2.4 & 14.8 & 7.5 & 16.4 \\
\hline 22 & 02830Gh_26 & 1.5 & 9.9 & 6.3 & 9.3 & 45549Gh_NA & 9.2 & 14.6 & 7.6 & 14.3 \\
\hline 23 & 37369Gh_26 & 1.5 & 9.9 & 6.3 & 9.3 & 08140Gh_26 & 9.2 & 14.4 & 7.5 & 13.8 \\
\hline 24 & 08149Gh_26 & 1.5 & 9.9 & 6.3 & 9.3 & 60525Gb_26 & 5.3 & 14.0 & 7.4 & 17.4 \\
\hline 25 & 25982Gh_26 & 1.5 & 9.9 & 6.3 & 9.3 & 33352Gh_26 & 6.1 & 13.7 & 7.8 & 13.1 \\
\hline 26 & 08152Gh_26 & 1.5 & 9.9 & 6.3 & 9.3 & 08155Gh_26 & 6.1 & 13.7 & 7.8 & 13.1 \\
\hline 27 & 24926Gh_26 & 1.5 & 9.9 & 6.3 & 9.3 & 00667Gh_26 & 6.1 & 13.5 & 7.7 & 13.1 \\
\hline 28 & 08155Gh_26 & 1.5 & 9.9 & 6.3 & 9.3 & 00592Gh_26 & 6.1 & 13.3 & 7.6 & 13.1 \\
\hline 29 & 08153Gh_26 & 1.5 & 9.8 & 6.3 & 9.3 & 24926Gh_26 & 6.1 & 13.3 & 7.6 & 13.1 \\
\hline 30 & 20910Gh_NA & 6.7 & 9.7 & 6.5 & 9.2 & 08162Gh_NA & 6.1 & 13.3 & 7.6 & 11.9 \\
\hline 31 & 21766Gh_26 & 6.7 & 9.7 & 6.5 & 9.2 & 19454Gh_26 & 6.1 & 13.1 & 7.4 & 13.1 \\
\hline 32 & 50696Gb_26 & 6.7 & 9.7 & 6.5 & 9.2 & 20903Gh_26 & 6.2 & 13.1 & 7.4 & 11.9 \\
\hline 33 & 51115Gb_26 & 6.7 & 9.7 & 6.5 & 9.2 & 08161Gh_NA & 6.2 & 13.1 & 7.4 & 11.9 \\
\hline 34 & 50256Gb_26 & 6.7 & 9.7 & 6.5 & 9.2 & 21388Gh_26 & 6.1 & 13.1 & 7.6 & 11.9 \\
\hline 35 & 25680Gh_26 & 6.7 & 9.7 & 6.5 & 9.2 & 37369Gh_26 & 6.1 & 13.1 & 7.6 & 13.1 \\
\hline 36 & 08185Gh_26 & 6.7 & 9.7 & 6.5 & 9.2 & 08152Gh_26 & 6.1 & 13.1 & 7.6 & 11.9 \\
\hline 37 & SSR & 6.7 & 9.7 & 6.5 & 9.2 & 08159Gh_NA & 6.1 & 13.1 & 7.6 & 11.9 \\
\hline 38 & 61504Gt_26 & 6.7 & 9.7 & 6.5 & 9.2 & 08149Gh_26 & 6.1 & 13.0 & 7.4 & 11.9 \\
\hline 39 & 56400Gb_26 & 6.7 & 9.6 & 6.4 & 9.2 & 08144Gh_26 & 6.1 & 12.9 & 7.3 & 13.1 \\
\hline 40 & 08184Gh_26 & 6.7 & 9.5 & 6.2 & 9.2 & 53682Gb_26 & 6.1 & 12.9 & 7.4 & 13.1 \\
\hline 41 & 20903Gh_26 & 1.5 & 9.4 & 6.1 & 9.3 & 36393Gh_26 & 6.2 & 12.9 & 7.3 & 13.1 \\
\hline 42 & 08140Gh_26 & 0.0 & 9.4 & 6.3 & 8.9 & 22395Gh_26 & 9.2 & 12.7 & 7.1 & 13.8 \\
\hline
\end{tabular}


Table 5 continued

\begin{tabular}{|c|c|c|c|c|c|c|c|c|c|c|}
\hline & \multicolumn{5}{|c|}{ POP1: MD26ne x Mac7 1238Ne } & \multicolumn{5}{|c|}{ POP2: MD26ne x Mac7 0238Ne } \\
\hline & SNPs & $\begin{array}{l}\text { Kosambi } \\
(\mathrm{cM})\end{array}$ & $\begin{array}{l}\text { SMA } \\
(-\log \mathrm{P})\end{array}$ & $\begin{array}{l}\text { MTA } \\
(-\log \mathrm{P})\end{array}$ & $\begin{array}{l}\text { IM } \\
\text { (LOD) }\end{array}$ & SNPs & $\begin{array}{l}\text { Kosambi } \\
(\mathrm{cM})\end{array}$ & $\begin{array}{l}\text { SMA } \\
(-\log \mathrm{P})\end{array}$ & $\begin{array}{l}\text { MTA } \\
(-\log \mathrm{P})\end{array}$ & $\begin{array}{l}\text { IM } \\
\text { (LOD) }\end{array}$ \\
\hline 43 & 08144Gh_26 & 0.0 & 9.4 & 6.3 & 8.9 & 16351Gh_NA & 6.1 & 12.6 & 7.2 & 13.1 \\
\hline 44 & 26493Gh_26 & 0.0 & 9.4 & 6.3 & 8.9 & 36874Gh_26 & 6.1 & 12.6 & 7.2 & 13.1 \\
\hline 45 & 45549Gh_NA & 0.0 & 9.4 & 6.3 & 8.9 & 08153Gh_26 & 6.1 & 12.6 & 7.2 & 11.9 \\
\hline 46 & 35898Gh_NA & 0.0 & 9.4 & 6.3 & 8.9 & 32829Gh_26 & 6.1 & 12.5 & 7.1 & 13.1 \\
\hline 47 & 08138Gh_26 & 0.0 & 9.4 & 6.3 & 8.9 & 25982Gh_26 & 6.1 & 12.5 & 7.1 & 11.9 \\
\hline 48 & 16348Gh_26 & 0.0 & 9.4 & 6.3 & 8.9 & 24215Gh_26 & 6.2 & 12.4 & 7.0 & 11.9 \\
\hline 49 & 08136Gh_NA & 0.0 & 9.4 & 6.3 & 8.9 & 42398Gh_26 & 6.1 & 12.3 & 6.9 & 13.1 \\
\hline 50 & 22721Gh_NA & 6.7 & 9.4 & 6.3 & 9.2 & 00492Gh_NA & 6.2 & 12.3 & 6.9 & 11.9 \\
\hline 51 & 20683Gh_26 & 6.7 & 9.2 & 6.3 & 9.2 & 49071Gh_26 & 6.1 & 12.1 & 6.8 & 11.9 \\
\hline 52 & 20909Gh_26 & 6.7 & 9.1 & 6.2 & 9.2 & 02830Gh_26 & 6.1 & 12.1 & 7.2 & 13.1 \\
\hline 53 & 22395Gh_26 & 0.0 & 8.1 & 5.6 & 8.9 & 45674Gh_NA & 10.9 & 11.1 & 4.6 & 14.0 \\
\hline 54 & 45674Gh_NA & 0.0 & 7.8 & 5.5 & 8.9 & 08157Gh_26 & 7.7 & 10.2 & 4.1 & 10.6 \\
\hline 55 & 60525Gb_26 & 7.5 & 7.7 & 5.6 & 9.3 & 00379Gh_26 & 0.0 & 10.1 & 3.4 & 12.5 \\
\hline
\end{tabular}

significantly associated with the nectariless trait on Chr. 12 and 26, respectively. Additionally, interval mapping (IM) was employed to search for QTLs on the genome location flanked by two SSR markers (Table 1) and marker trait analysis (MTA) was also used to search for QTL on each chromosome (12 and 26).

Figure 2 shows the respective nectariless QTL region located on Chr. 12 and 26. Previous research has shown that two genes $\left(\mathrm{Ne}_{1}\right.$ and $\left.\mathrm{Ne}_{2}\right)$ are responsible for nectary formation with $\mathrm{Ne}_{1}$ localized to $\mathrm{Chr}$. 12 and having a major effect on presence of leaf nectaries as well as a modifying effect on bract nectaries (Meyer and Meyer 1961; Holder et al. 1968). For Chr. 12, no significant linkage was found between SNP markers and our $\mathrm{F}_{2}$ derived nectariless phenotypic data while significant linkage was found on Chr. 26. As shown in Fig. 2, POP1-3 placed the two SSR markers on Chr. 26 whereas POP4 had no SSR markers linked on Chr. 26.

For POP1-3, eight polymorphic SNP markers that consistently appeared in the three mapping populations were identified (Table 4). POP4 was omitted because no significant linkage was found between the SNP markers and $F_{2}$ phenotypic data. In contrast, the SNP markers for POP1 and POP2 showed highly significant linkage between the SNPs and the trait ($\log$ P of SMA and MTA: $>10$ and $>6$, respectively, and LOD of IM > 10) and markers on POP3 were also significant, but to a lesser degree. The results identified similar QTL regions for the three different map populations, although the linkage on POP3 was not as significant as POP1-2.

For POP1 and POP2, 54 SNPs and 2 SSR markers (DPL0379 and DPL0565) were linked to a nectariless QTL in Chr. 26.

Figure 3 shows QTL maps constructed from individual populations (POP1-3) and a consensus map over all three populations. The three linkage maps are very closely matched to each other and eight SNP markers (marked with asterisks) were common to all three populations. The consensus map of three populations indicates that the map location at $30.5 \mathrm{cM}$ is highly associated with the nectariless trait and can be used as a molecular marker for the trait selection. As shown in the consensus map, two co-located SSRs are also located in the same region, confirming a QTL region associated with the nectariless trait on Chr. 26. Notably, SNPs whose physical chromosomal location were previously unknown were also included in the analysis and some of those SNPs can now be assigned to Chr. 26 (Table 5). 
Fig. 4 Theoretical genotypes from a cross of a homozygous nectaried parent and a homozygous nectariless parent with possible F2 progeny phenotypes and genotypes
Cross

$\mathrm{Ne}_{1} \mathrm{Ne}_{1} \mathrm{Ne}_{2} \mathrm{Ne}_{2} \quad x \quad \mathrm{ne}_{1} \mathrm{ne}_{1} \mathrm{ne}_{2} \mathrm{ne}_{2}$

F1 $\mathrm{Ne}_{1} \mathrm{ne}_{1} \mathrm{Ne}_{2} \mathrm{ne}_{2}$

Self Pollinate

F2

Possible F2 Genotypes

\begin{tabular}{|c|c|c|c|c|}
\hline Gametes & $\mathrm{Ne}_{1} \mathrm{Ne}_{2}$ & $\mathrm{Ne}_{1} \mathrm{ne}_{2}$ & $\mathrm{ne}_{1} \mathrm{Ne}_{2}$ & $\mathrm{ne}_{1} \mathrm{ne}_{2}$ \\
\hline $\mathrm{Ne}_{1} \mathrm{Ne}_{2}$ & $\mathrm{Ne}_{1} \mathrm{Ne}_{1} \mathrm{Ne}_{2} \mathrm{Ne}_{2}$ & $\mathrm{Ne}_{1} \mathrm{Ne}_{1} \mathrm{Ne}_{2} \mathrm{ne}_{2}$ & $\mathrm{Ne}_{1} \mathrm{ne}_{1} \mathrm{Ne}_{2} \mathrm{Ne}_{2}$ & $\mathrm{Ne}_{1} \mathrm{ne}_{1} \mathrm{Ne}_{2} \mathrm{ne}_{2}$ \\
\hline $\mathrm{Ne}_{1} \mathrm{ne}_{2}$ & \multirow{3}{*}{$\begin{array}{l}\mathrm{Ne}_{1} \mathrm{Ne}_{1} \mathrm{Ne}_{2} \mathrm{ne}_{2} \\
\mathrm{Ne}_{1} \mathrm{ne}_{1} \mathrm{Ne}_{2} \mathrm{Ne}_{2} \\
\mathrm{Ne}_{1} \mathrm{ne}_{1} \mathrm{Ne}_{2} \mathrm{ne}_{2}\end{array}$} & $\mathrm{Ne}_{1} \mathrm{Ne}_{1} \mathrm{ne}_{2} \mathrm{ne}_{2}$ & $\mathrm{Ne}_{1} \mathrm{ne}_{1} \mathrm{Ne}_{2} \mathrm{ne}_{2}$ & $\mathrm{Ne}_{1} \mathrm{ne}_{1} \mathrm{ne}_{2} \mathrm{ne}_{2}$ \\
\hline $\mathrm{ne}_{1} \mathrm{Ne}_{2}$ & & $\mathrm{Ne}_{1} \mathrm{ne}_{1} \mathrm{Ne}_{2} \mathrm{ne}_{2}$ & $\mathrm{ne}_{1} \mathrm{ne}_{1} \mathrm{Ne}_{2} \mathrm{Ne}_{2}$ & $n e_{1} \mathrm{ne}_{1} \mathrm{Ne}_{2} \mathrm{ne}_{2}$ \\
\hline ne $_{1} \mathrm{ne}_{2}$ & & $\mathrm{Ne}_{1} \mathrm{ne}_{1} \mathrm{ne}_{2} \mathrm{ne}_{2}$ & $\mathrm{ne}_{1} \mathrm{ne}_{1} \mathrm{Ne}_{2} \mathrm{ne}_{2}$ & $n e_{1} n e_{1} n e_{2} n e_{2}$ \\
\hline
\end{tabular}

\section{Discussion}

The nectariless trait has proven to be a valuable agronomic trait that decreases the cotton plant's attractiveness to some insect pests. The trait has been shown to confer tolerance against pink boll worm (Percy 2001, Khan et al. 2002, flint et al. 1991), Lepidoptera (Lukefahr and Rhyne 1960; Soares et al. 1998) and tarnished plant bugs (Platt and Steward 1999). Attempts have been made to develop nectariless cultivars (Meredith 2006), but these efforts have been frustrated by the inability to accurately select for the trait phenotypically. To increase selection efficiency and allow marker assisted selection to be used, efforts have been made to develop nectariless markers including random amplified polymorphic DNA (RAPD) markers (Sajid-ur-rahman et al. 2008; Amir et al. 2002), but so far no usable markers are publicly available.

The first obstacle in developing SSR or SNP markers was to be able to accurately phenotype the progeny from $\mathrm{F}_{2}$ mapping populations. As described in the results section, the nectariless trait is controlled by two genes with possible differential (epistatic) expression for leaf nectaries and the overall expression affected by environmental conditions. This makes traditional genetic segregation ratios difficult to determine as illustrated in Fig. 4.

To improve the chances of distinguishing between homozygous and heterozygous plants, four mapping populations with different parental combinations were used and two leaves per plant were scored using a digital microscope at $10 \times$ magnification. Digital images were made of the leaves and nectaries and the leaf images used for scoring. This greatly reduced the number of heterozygous plants that were scored as nectariless, but could not eliminate the heterozygous genotypes that did not produce a nectary. These possible mis-scored genotypes are highlighted in light green. While it was easier to score for heterozygous nectaried plants, there was also the possibility of misscores with a heterozygote being scored as homozygous nectaried which are highlighted in light blue. It is possible that $\mathrm{N} e_{1}$ and $\mathrm{Ne}_{2}$ each have a different effect on a different plant part, while also having modifying effects on the other plant part (Holder et al. 1968; Waghmare et al. 2005). This is not uncommon in upland cotton where two genes, present on two homeologous chromosomes have diverged and have differential expression in different plant parts (Wilson and Smith 1977; Lee 1962, 1965).

Despite the difficulties in accurately scoring the phenotypes, analyses of the different populations, identified a consistent QTL region on Chr. 26 for POP1-3. POP1 and POP2 exhibited highly significant linkage association between the trait and Pop3 was significantly linked. The genetic markers were not always in the same order and distances varied, likely due to the small population size of each population. Markers highlighted on Table 5 will be further investigated as molecular markers to use for MAS for the nectariless trait. We expected to identify a QTL region on Chr. 12, but did not identify any statistically significant markers with these mapping populations. This may be due to a combination of small population size, the fact that the sequence in the chromosomal 
Table 3 The number of SNPs used for linkage analyses after quality processing

\begin{tabular}{|c|c|c|c|c|c|c|c|c|c|c|c|c|}
\hline \multirow[b]{2}{*}{$\begin{array}{l}\text { Chr } \\
\text { Location }\end{array}$} & \multicolumn{3}{|c|}{$\begin{array}{l}\text { POP1 } \\
\text { MD26ne } e^{c} \text { Mac7 1238Ne }\end{array}$} & \multicolumn{3}{|c|}{$\begin{array}{l}\text { POP2 } \\
\text { MD26ne x Mac7 0238Ne }\end{array}$} & \multicolumn{3}{|c|}{$\begin{array}{l}\text { POP3 } \\
\text { A1006ne x JACOglNe }\end{array}$} & \multicolumn{3}{|c|}{$\begin{array}{l}\text { POP4 } \\
\text { STVglNe x FM832ne }\end{array}$} \\
\hline & 12 & 26 & $\mathrm{n} / \mathrm{a}$ & 12 & 26 & $\mathrm{n} / \mathrm{a}$ & 12 & 26 & $\mathrm{n} / \mathrm{a}$ & 12 & 26 & $\mathrm{n} / \mathrm{a}$ \\
\hline Nr. SNPs Before ${ }^{a}$ & 535 & 542 & 11,777 & 535 & 542 & 11,777 & 115 & 125 & 2813 & 535 & 542 & 11,777 \\
\hline $\begin{array}{l}\text { Nr. SNPs } \\
\text { After }^{\text {b }}\end{array}$ & 127 & 101 & 3306 & 133 & 103 & 3205 & 77 & 62 & 1577 & 170 & 153 & 2855 \\
\hline
\end{tabular}

region containing the nectariless trait is similar for the two homeolgous chromosomes 12 and 26 which may confound the analysis. While it would be ideal to have DNA markers linked to both genes, because of the extreme difficulty in accurate phenotypic scoring, even markers linked to $n e_{2}$ will improve the efficiency and ease of selection. This is especially true in the early stages of cultivar development where large numbers of plants need to be grown and carried forward to the next generation if there is no efficient MAS. The $n e_{2}$ markers will help reduce the number of plants carried forward.

Further research is underway to identify SSR / SNPs for Chr. 12 by developing larger mapping populations with different parental combinations. The parents for these populations were checked for homozygosity by selecting individual plants with the nectaried or nectariless phenotype and then growing them out as a progeny row to check for segregation in the subsequent generation before using them as parents. $F_{3}$ progeny from the $F_{2}$ plants, used for mapping populations, can also be grown out to catch some of the mis-scores, but will be subject to the same phenotypic scoring challenges that are faced for the $\mathrm{F}_{2}$ plants. Additional parental combinations are also being determined using genomic sequence information obtained from sequences in the putative chromosomal regions for the nectariless trait (Saski et al. 2017). SNPS are also being developed directly from these genomic sequences and the framework cotton genomic sequence (Saski et al. 2017). The markers and information from a recent publication that mapped the trait in diploid $G$. arboreum may also help refine the search for markers on chromosome 12 (Hu et al. 2020).

Acknowledgement The authors thank colleagues in the Crop Genetics Research Unit and Genomics and Bioinformatics Research Unit for their technical and advisory support.

Authors' contributions All authors contributed to the study conception and design. Material preparation and data collection were performed by Sang-Hyuck Park and Jodi Scheffler, analyses were performed by Sang-Hyuck Park, Jodi Scheffler and Jeffery Ray. The first draft of the manuscript was written by Sang-Hyuck Park and all authors commented on previous versions of the manuscript. All authors read and approved the final manuscript.

Funding The research was supported by USDA projects 6066-21000-052-00D and 6066-21310-005-00D.

\section{Code availability N/A}

\section{Compliance with ethical standards}

Conflicts of interest The authors have no relevant financial or non-financial interests to disclose and have no conflicts of interest to declare that are relevant to the content of this article.

\section{Consent to participate Yes}

\section{Consent for publication Documents on file}

Disclaimer Mention of trade names or commercial products in this publication is solely for the purpose of providing specific information and does not imply recommendation or endorsement by the US. Department of Agriculture (USDA). USDA is an equal opportunity provider and employer.

Availability of data and material Anything not in the paper is available on request. 
Open Access This article is licensed under a Creative Commons Attribution 4.0 International License, which permits use, sharing, adaptation, distribution and reproduction in any medium or format, as long as you give appropriate credit to the original author(s) and the source, provide a link to the Creative Commons licence, and indicate if changes were made. The images or other third party material in this article are included in the article's Creative Commons licence, unless indicated otherwise in a credit line to the material. If material is not included in the article's Creative Commons licence and your intended use is not permitted by statutory regulation or exceeds the permitted use, you will need to obtain permission directly from the copyright holder. To view a copy of this licence, visit http://creativecommons.org/licenses/by/4.0/.

\section{References}

Adjeimaafo IK, Wilson LT (1983) Association of cotton nectar production with Heliothis-Punctigera (Lepidoptera, Noctuidae) oviposition. Environ Entomol 12:1166-1170

Amir AH, Malik TA, Raza H, Rahman M (2002) DNA marker studies for leaf nectaries in upland cotton. Asian J Plant Sci $1: 395-396$

Benedict JH, Leigh TF, Hyer AH, Wynholds PF (1981) Nectariless cotton: Effect on growth, survival, and fecundity of Lygus Bug. Crop Sci 21:28-30

Cardoso-Gustavson P, Davis AR (2015) Is nectar reabsorption restricted by the stalk cells of floral and extrafloral nectary trichomes? Plant Biol 17:134-146

Chatt EC, Mahalim S-N, Mohd-Fadzil N-A, Roy R, Klinkenberg PM, Horner HT, Hampton M, Carter CJ, Nikolau BJ (2019) Systems analysis of key metabolic modules of floral and extrfloral nectaries of cotton. bioRXiv doi.org/https:// doi.org/10.1101/857771

Du X, Huang G, He S, Yang Z, Sun G, Ma X, Li N, Zhang X, Sun J, Liu M, Jia Y, Pan Z, Gong W, Liu Z, Zhu H, Ma L, Liu F, Yang D, Wang F, Fan W, Gong Q, Peng Z, Wang L, Wang X, Xu S, Shang H, Lu C, Zheng H, Huang S, Lin T, Zhu Y, Li F (2018) Resequencing of 243 diploid cotton accessions based on an updated A genome identities the genetic basis of key agronomic traits. Nat Genet 50:796-802

Flint HM, Wilson FD, Parks NJ, Reynoso RY, Stapp BR, Szaro JL (1991) Suppression of pink-bollworm and effect on beneficial insects of a nectariless okra-leaf cotton germplasm line. Entomol Res 81:379-384

Heil M (2015) Extrafloral nectar at the plant-insect interface: A spotlight on chemical ecology, phenotypic plasticity, and food webs. Ann Rev Entomol 60:213-232

Holder DG, Jenkins JN, Maxwell FG (1968) Duplicate linkage of glandless and nectariless genes in upland cotton Gossypium hirsutum L. Crop Sci 8:577-580

Hou MY, Cai CP, Zhang SW, Guo WZ, Zhang TZ, Zhou BL (2013) Construction of microsatellite-based linkage map and mapping of nectarilessness and hairiness genes in Gossypium tomentosum. J Genet 92:445-459

Hu W, Qin W, Jin Y, Wang P, Yan Q, Li F, Yang Z (2020) Genetic and evolution analysis of extrafloral nectary in cotton. Plant Biotechnol J 18:2081-2095
Hulse-Kemp AM, Lemm J, Plieske J, Ashrafi H, Buyyarapu R, Fang DD, Frelichowski J, Giband M, Hague S, Hinze LL, Kochan KJ, Riggs PK, Scheffler JA et al (2015) Development of a $63 \mathrm{~K}$ SNP array for cotton and high-density mapping of intraspecific and interspecific populations of Gossypium spp. Genes Genomes Genet 5:1187-1209

Joobeur T, Periam N, Vicente MC, King GJ, Arus P (2000) Development of a second generation linkage map for almond using RAPD and SSR markers. Genome 43:649-655

Kottapalli P, Ulloa M, Kottapalli KR, Payton P, Burke J (2016) SNP marker discovery in pima cotton (Gossypium barbadense L.) leaf transcriptomes. Genomics Insights 9:51-60

Lee JS (1962) Genetical studies concerning the distribution of pigment glands in the cotyledons and leaves of upland cotton. Genetics 47:131-142

Lee JS (1965) The genomic allocations of the principal foliargland loci in Gossypium hirsutum and Gossypium barbadense. Evolution 19:182-188

Lee J (1973) The inheritance of gossypol in Gossypium II inheritance of seed gossypol in two strains of cultivated Gossypium barbadense L. Genetics 75:259-264

Liu S, Saha S, Stelly D, Burr B, Cantrell RG (2000) Chromosomal assignment of microsatellite loci in cotton. J Hered 91:326-332

Llandres AL, Verdeny-Vilalta O, Jean J, Goebel F-R, Seydi O, Brevault T (2019) Cotton extrafloral nectaries as indirect defence against insect pests. Basic Appl Ecol 37:24-34

Lukefahr MJ, Rhyne C (1960) Effects of nectariless cotton on populations of three Lepidopterous insects. Econ Entomol 53:242-244

Meredith WR (2006) Registration of MD 15 upland cotton germplasm. Crop Sci 46:2722-2723

Meredith WR (2013) Registration of MD25-26ne, MD25-27, and MD25-87 germplasm lines of cotton with superior yield, fiber quality, and pest resistance. J Plant Regist 7:327-333

Meyer JR, Meyer VG (1961) Origin and inheritance of nectariless cotton. Crop Sci 1:167-169

Paiva EAS (2017) How does the nectar of stomata-free nectaries cross the cuticle? Acta Botanica Brasilica 31:525-530

Palombi MA, Damiano C (2002) Comparison between RAPD and SSR molecular markers in detecting genetic variation in kiwifruit (Actinidia deliciosa A. Chev). Plant Cell Rep 20:1061-1066

Park S-H, Scheffler J, Scheffler B, Cantrell CL, Pauli CS (2019) Chemical defense responses of upland cotton, Gossypium hirsutum L. to physical wounding. Plant Direct 3:5. https:// doi.org/10.1002/pld3.141

Rhyne CL (1965) Inheritance of extra-floral nectaries in cotton. Adv Front Plant Sci 13:121-137

Romano GB, Scheffler JA (2008) Lowering seed gossypol content in glanded cotton (Gossypium hirsutum L.) lines. Plant Breed 127:619-624

Roy R, Schmitt AJ, Thomas JB, Carter CJ (2017) Review: Nectar biology: from molecules to ecosystems. Plant Sci 262:148-164

SAS Institute I (2015a) Step-by-Step Guide to QTL Analysis

SAS Institute I (2015b) JMP ${ }^{\circledR} 12$ Multivariate Methods 
Saski CA, Scheffler BE, Hulse-Kemp AM, Liu B, Song Q, Ando A, Stelly DM, Scheffler JA, Grimwood J, Jones DC, Peterson DG, Schmutz J, Chen ZJ (2017) Sub genome anchored physical frameworks of the allotetraploid Upland cotton (Gossypium hirsutum L.) genome, and an approach toward reference-grade assemblies of polyploids. Sci Rep $7: 15274$

Schuler GD (1998) Electronic PCR: Bridging the gap between genome mapping and genome sequencing. Trends Biotechnol 16:456-459

Stapel JO, Cortesero AM, De Moraes CM, Tumlinson JH, Lewis WJ (1997) Extrafloral nectar, honeydew, and sucrose effects on searching behavior and efficiency of Microplitis croceipes (Hymenoptera: Braconidae) in cotton. Environ Entomol 26:617-623

Ur-Rahman S, Malik TA, Ashraf M, Ahsan M (2008) Identification of DNA marker for nectariless trait in cotton using Random Amplified Polymorphic DNA technique. Pak J Bot 40:1711-1719

Wackers FL, Zuber D, Wunderlin R, Keller F (2001) The effect of herbivory on temporal and spatial dynamics of foliar nectar production in cottn and castor. Ann Bot Lond $87: 365-370$
Waghmare VN, Rong JK, Rogers CJ, Pierce GJ, Wendel JF, Paterson AH (2005) Genetic mapping of a cross between Gossypium hirsutum (cotton) and the Hawaiian endemic, Gossypium tomentosum. Theor Appl Genet 111:665-676

Wilson FD, Smith JN (1977) Variable expressivity and gene action of gland-determining alleles in Gossypium hirsutum L. Crop Sci 17:539-543

Wilson RL, Wilson FD (1976) Nectariless and glabrous cottons: Effect on pink bollworm in Arizona. J Econ Entomol 69:623-624

Xu Z, Kohel RJ, Song G, Cho J, Yu J, Yu S, Tomkins J, Yu JZ (2008) An integrated genetic and physical map of homoeologous chromosomes 12 and 26 in upland cotton (G. hirsutum L.). BMC Genom 9:108 doi.org/https://doi. org/10.1186/1471-2164-9-108

Yu J, Jung S, Cheng CH, Ficklin SP, Lee T, Zheng P, Jones D, Percy RG, Main D (2014) CottonGen: a genomics, genetics and breeding database for cotton research. Nucleic Acids Res 42:D1229-D1236

Publisher's Note Springer Nature remains neutral with regard to jurisdictional claims in published maps and institutional affiliations. 